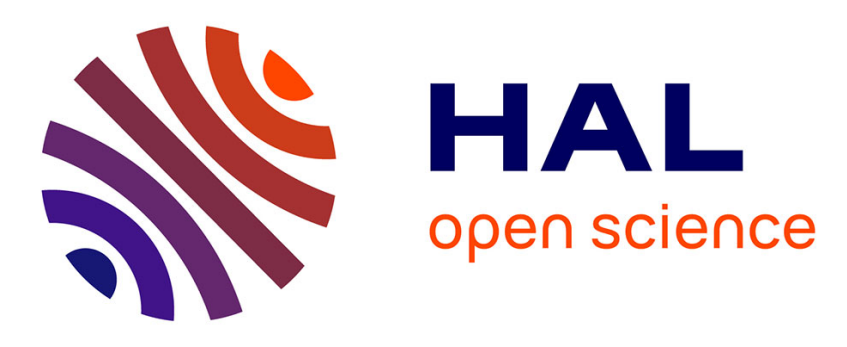

\title{
Large amplitude motions within molecules trapped in solid parahydrogen
}

\author{
Alejandro Gutiérrez-Quintanilla, Michèle Chevalier, Justinas Ceponkus, \\ Rolando Lozada-Garcia, Jean-Michel Mestdagh, Claudine Crépin
}

\section{To cite this version:}

Alejandro Gutiérrez-Quintanilla, Michèle Chevalier, Justinas Ceponkus, Rolando Lozada-Garcia, Jean-Michel Mestdagh, et al.. Large amplitude motions within molecules trapped in solid parahydrogen. Faraday Discussions, 2018, 212, pp.499-515. 10.1039/C8FD00080H . hal-02329484

\section{HAL Id: hal-02329484 \\ https://hal.science/hal-02329484}

Submitted on 22 Sep 2020

HAL is a multi-disciplinary open access archive for the deposit and dissemination of scientific research documents, whether they are published or not. The documents may come from teaching and research institutions in France or abroad, or from public or private research centers.
L'archive ouverte pluridisciplinaire HAL, est destinée au dépôt et à la diffusion de documents scientifiques de niveau recherche, publiés ou non, émanant des établissements d'enseignement et de recherche français ou étrangers, des laboratoires publics ou privés. 


\title{
Faraday Discussions
}

\section{ARTICLE}

\section{Large Amplitude Motions within Molecules Trapped in Solid Parahydrogen}

Received 00th January 20xx, Accepted 00th January 20xx

DOI: $10.1039 / x 0 x \times 00000 x$

www.rsc.org/

\begin{abstract}
Alejandro Gutiérrez-Quintanilla, ${ }^{a, b}$ Michèle Chevalier, ${ }^{a}$ Justinas Ceponkus, ${ }^{c}$ Rolando R. LozadaGarcía, ${ }^{\mathrm{a}, \mathrm{b}^{\dagger}}$ Jean-Michel Mestdagh, ${ }^{\mathrm{d}}$ and Claudine Crépin ${ }^{\mathrm{a}}$

Molecules of the $\beta$-diketone and $\beta$-dialdehyde families were trapped in solid parahydrogen $\left(p \mathrm{H}_{2}\right)$ to investigate the vibrational behavior of systems including an intramolecular hydrogen bond (IHB). In the simplest $\beta$-diketone, acetylacetone (AcAc), the $\mathrm{H}$ transfer related to the IHB is coupled with methyl torsions. In $p \mathrm{H}_{2}$, the study of the nuclear spin conversion (NSC) in methyl groups allows the characterisation of the influence of these large amplitude motions on the vibrational modes. The deuteration of the $\mathrm{OH}$ group involved in the IHB has important consequences on the vibrational spectrum of the molecule and evidence of NSC in methyl groups is difficult to get. In the chlorine derivative (3chloroacetylacetone), the $\mathrm{H}$-transfer is not anymore coupled with methyl torsion, and NSC has undetectable effects on the IR spectrum. A search of $\mathrm{H}$ tunneling splitting in the IR spectrocopy of $\beta$-dialdehydes trapped in $p \mathrm{H}_{2}$ was performed. A few modes of 2-chloromalonaldehyde appear as doublets and were assigned to tunnelling levels. The spectroscopic results related to large amplitude motions are detailed and discussed, highlighting puzzling effects.
\end{abstract}

\section{Introduction}

Parahydrogen $\left(p \mathrm{H}_{2}\right)$ solid offers specific qualities as a matrix host that allows great improvements in molecular spectroscopy and photochemistry of matrix isolated species. ${ }^{1-5}$ Due to the large zero-point motion of hydrogen molecules in the solid, the distance between nearest neighbours is as large as in solid argon $\left(0.379 \mathrm{~nm}\right.$ in $p \mathrm{H}_{2}$ vs $0.376 \mathrm{~nm}$ in $\left.\mathrm{Ar}\right){ }^{6}$ with the advantage that this "quantum" solid is especially soft for the trapped molecular guests. This has two main spectroscopic consequences. First, the bands are essentially homogeneously broadened because of the lack of multiple rigid trapping sites. Second, the small molecules can rotate almost freely. Hence, high resolution spectra can be obtained with rotational resolution. ${ }^{1}$ The situation is more complex with non-linear

\footnotetext{
${ }^{a .}$ Institut des Sciences Moléculaires d'Orsay (ISMO), UMR 8214, CNRS, Univ. ParisSud, Université Paris-Saclay UMR 8214, F-91405 Orsay, France.

${ }^{b}$. Instituto Superior de Tecnologías y Ciencias Aplicadas (InSTEC), Universidad de La Habana. Ave. Salvador Allende No. 1110, Quinta de los Molinos, La Habana 10400, Cuba.

c. Institute of Chemical Physics, Vilnius University, Sauletekio av. 9 bat. III, L-10222 Vilnius, Lithuania

d. LIDYL, CEA, CNRS, Université Paris-Saclay, F-91191 Gif-sur-Yvette, France

† Present address: Thales SFI, THALES, 14 rue Grange Dame Rose, 78014 VélizyVillacoublay, France

Electronic Supplementary Information (ESI) available: [details of any supplementary information available should be included here]. See DOI: $10.1039 / \times 0 \times x 00000 x$
}

molecules when both small and large moments of inertia are present. For example with $\mathrm{CH}_{3} \mathrm{~F}$, only the rotation about the $\mathrm{C}$ $\mathrm{F}$ axis is weakly perturbed by the $\mathrm{pH}_{2}$ environment. ${ }^{7}$ Similarly, large amplitude motions such as methyl torsions seem preserved in $\mathrm{pH}_{2}$. The spectra of large species are also expected to be simplified in this cryogenic quantum host, allowing the analysis of intrinsic properties of the molecular guest.

Our group is interested in using the $p \mathrm{H}_{2}$ matrix isolation technique to study molecules where an intramolecular hydrogen bond (IHB) is coupled with specific vibrational modes of the molecule and leads to observable broadening. ${ }^{8,9}$ Our goal is to explore the $\mathrm{H}$ transfer as a large amplitude motion within these molecules, possibly coupled with other large amplitude motions.

In the $\beta$-diketone and $\beta$-dialdehyde families, the molecules that are present in the gas phase as chelated enols in their most stable form are good candidates for such studies. A resonant assisted hydrogen bond (RAHB), due to a $\pi$ electronic delocalization in the pseudo cycle of the molecule, enhances the strength of IHB. ${ }^{10}$ The molecules of interest in this paper are shown in their chelated enol form in Figure 1. 


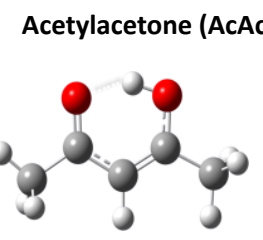

3-Chloroacetylacetone (AcAcCl)

Malonaldehyde (MA)

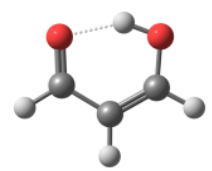

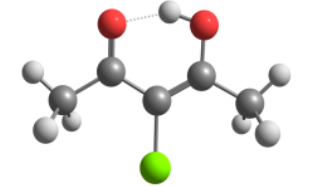

2-Chloromalonaldehyde (MACl)

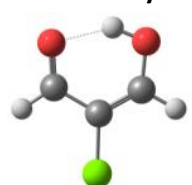

Figure 1: Chelated enol conformers of the molecules under investigation with their short names used in the paper.

The case of Acetylacetone (AcAc) is especially interesting because three entangled large amplitude motions are at play in this molecules, the $\mathrm{H}$-transfer being coupled with the torsion of the two methyl groups. The first results on large amplitude motions in AcAc were published in a former work of our group where the IR spectrum of AcAc trapped in $p \mathrm{H}_{2}$ was found to change at a very long time scale. ${ }^{11}$ This behaviour was assigned to a Nuclear Spin Conversion (NSC) process within the methyl groups, as explained further in the text. With NSC in methyl groups, this work offered a novel and promising tool to study infrared absorption spectra from levels differing only by a small amount of torsional excitation. The observed spectra revealed indeed a clear broadening of specific vibrational bands upon such torsional excitation, an information that can hardly be obtained by other techniques.

In the present paper, we discuss these results on AcAc in $p \mathrm{H}_{2}$ in terms (i) of quantum matrix effects, by comparison with AcAc in $n \mathrm{H}_{2}$, (ii) of deuteration effect, in experiments with double deuterated acetylacetone $(A C A C D 2$, where the D-atoms are carried by the $-\mathrm{OD}$ and $=\mathrm{CD}$ groups) in $p \mathrm{H}_{2}$, and (iii) of substituent effect, in experiments with 3-chloroacetylacetone (AcAcCl) in $p \mathrm{H}_{2}$. In solid $p \mathrm{H}_{2}$, it is difficult to get rid of orthohydrogen $\left(\mathrm{OH}_{2}\right)$ impurities and NSC process in $\mathrm{H}_{2}$ (conversion $o \mathrm{H}_{2} \rightarrow p \mathrm{H}_{2}$ ) can be followed through the time evolution of the guest bands perturbed by an $\mathrm{oH}_{2}$ neighbourhood. ${ }^{3}$ The additional experimental results, compared to those published in ref. 11, document this point also and bring a deeper investigation of the $\mathrm{AcAc} / p \mathrm{H}_{2}$ system.

In AcAc, because of the presence of methyl groups and their coupling with the $\mathrm{H}$ transfer, it is not possible to observe a splitting of vibrational levels due to the $\mathrm{H}$ tunnelling in the IHB. Even in the gas phase, vibrational bands are as broad as in $p \mathrm{H}_{2}$ matrix. ${ }^{12}$ In contrast, this tunnelling splitting was observed and measured in jet experiments for many vibrational modes of malonaldehyde (MA), the simplest $\beta$-dialdehyde. Unfortunately, its synthesis is difficult. We obtained only very preliminary results on $\mathrm{MA} / p \mathrm{H}_{2}$ samples. We preferred conducting experiments with the chlorine derivative $(\mathrm{MACl}$, see Figure 1) in $\mathrm{pH}_{2}$. We detected doublet lines in its $\mathrm{IR}$ spectrum which can be assigned to the $\mathrm{H}$ tunnelling splitting in specific vibrational levels. ${ }^{13}$ Surprisingly, similar doublets were

observed in argon matrices, whereas the $\mathrm{H}$-tunnelling of MA was completely quenched in that solid. ${ }^{14}$ Our preliminary results on the $\beta$-dialdehyde family highlight the advantages to study $\mathrm{H}$ tunnelling in $p \mathrm{H}_{2}$.

\section{Experimental}

\section{Chemicals and deuteration synthesis.}

Acetylacetone $\left(\mathrm{C}_{5} \mathrm{O}_{2} \mathrm{H}_{8}, 99.5 \%\right)$ was purchased from Fluka, 3chloroacetylacetone $\left(\mathrm{C}_{5} \mathrm{O}_{2} \mathrm{H}_{7} \mathrm{Cl}, 97 \%\right)$, and 2chloromalonaldehyde $\left(\mathrm{C}_{3} \mathrm{O}_{2} \mathrm{H}_{4}, 95 \%\right)$ from Acros.

Double deuterated acetylacetone (AcAcD2) was prepared following synthesis steps published in Dea Kin-Kin doctoral thesis, with small modifications. ${ }^{15}$ Only the hydrogen involved in the IHB and the olefinic one (the most labile hydrogens) were substituted by deuterium atoms. The whole procedure of deuteration can be examined in ref. 16. Roughly, synthesis consisted in refluxing, under dry conditions, a mixture of acetylacetone and deuterated water $\left(D_{2} \mathrm{O},>99.9 \%\right.$ from SigmaAldrich) for approximately 4 hours at $80-90^{\circ} \mathrm{C}$. After reaching equilibrium at room temperature, organic and aqueous phases were separated by a decantation process, adding sodium chloride $(\mathrm{NaCl},>99 \%$ from Sigma-Aldrich) and cooling the sample to improve the separation. We added a small quantity of sodium sulfate $\left(\mathrm{Na}_{2} \mathrm{SO}_{4},>99.5 \%\right.$ from Merck) to eliminate possible water impurities in the final product and decanted this mixture at the end.

A first qualitative test to evaluate deuteration was made through the comparison of the gas phase spectra of deuterated and non-deuterated acetylacetone (AcAcH8). The comparison between both spectra and those published by Ogoshi, ${ }^{17}$ confirmed the success of the deuteration. Attained yield for exchange (deuteration) with non-methyl hydrogens was in general around 90\%, value deduced from IR spectra in neon matrix. This value included double and mono deuteration, with a yield of AcAcD2 always above $65 \%$.

At the end of each synthesis, the final product was stored in a glass reservoir, connected to a vacuum line and degassed with freeze-pump-thaw cycles. Deuteration quality was maintained over long periods (months).

\section{Matrix isolation setups.}

The experimental set-ups have been described in details in some of our previous publications. ${ }^{9,16}$ Briefly, the experimental setup includes two helium cryostats: one closed cycle for the ortho/para-hydrogen conversion process (Air Products, Displex) and another for the sample deposition. In our first experiments, the latter cryostat was a liquid helium SMC flow cryostat $^{11}$ (minimum working temperature of $3.8 \mathrm{~K}$ ) and more recently this cryostat was replaced by a closed cycle helium one (ICE: Innovative Cryogenic Engineering, He Compressor: Sumitomo $\mathrm{F}-50$ ) reaching a minimum temperature of $2.8 \mathrm{~K}$. Both cryostats are connected through a stainless steel line. The host gas flux and the amount of vapour from the sample 


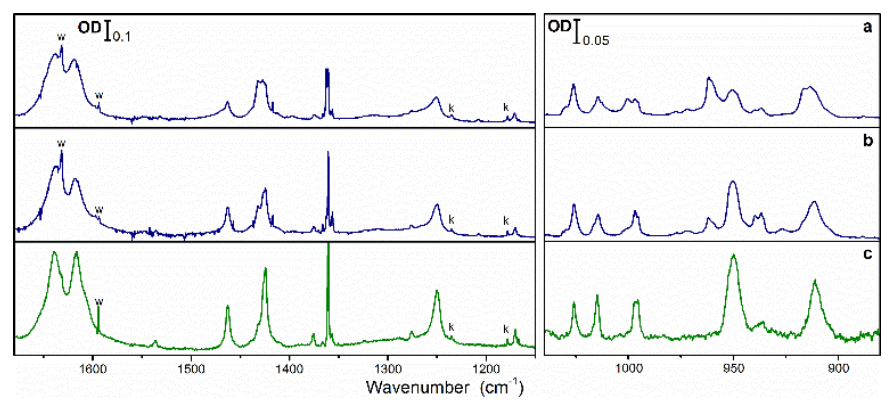

Figure 2: IR spectra of $\mathrm{AcAcH} 8$ isolated in $\mathrm{pH}_{2}$ (a) as deposited sample (the amount of $o \mathrm{H}_{2}$ is estimated $\leq 0.01 \%$ in this sample) (b) five days later (c) most stable species (AcAcH8 in the "A" level, see text) from ref.11. $k$ : keto lines, w: water.

entering the line were controlled by microvalves. The mixture of gases arrived directly in front of an internal diamond window, which is attached to the second stage of the cold head of the cryostat. Matrix quality was verified through the infrared spectrum of the deposited sample. The amount of ortho-hydrogen in the matrix can be controlled or increased by raising the temperature of the cryostat dedicated to the conversion. Annealing of $p \mathrm{H}_{2}$ matrices at $4.5 \mathrm{~K}$ was performed to get rid of parts of $f c c$ structures in the solid and to obtain only the stable $h c p$ lattice of $\mathrm{pH}_{2}{ }^{4}$ No spectral change was detected, indicating a lack of $f c c$ structures in our experimental conditions. In particular, we observed a weak amount of water in most of our samples and the IR signature of $\mathrm{H}_{2} \mathrm{O}$ in a $f c c$ surrounding ${ }^{18}$ was missing. The guest/host ratio was typically in the $1 / 1000$ to $1 / 2000$ range. The ratio is deduced from the ratio between hydrogen and guest bands.

Infrared spectra were acquired using a standard FT-IR spectrometer (Nicolet Nexus 670/870), and a liquid nitrogencooled MCT (HgCdTe: Mercury Cadmium Telluride) detector. The spectra were recorded in transmission mode with a 0.5 $\mathrm{cm}^{-1}$ resolution level. The IR beam path was purged with dry air.

It is important to note that a direct investigation of the $-\mathrm{OH}$ stretching mode (the most involved in the IHB) is impossible in the molecules studied here, because the corresponding IR band is too broad to be detected and analysed.

\section{Results and discussion}

Some of the results reported below appeared in previous publications with a short analysis. They are complemented here by additional studies to allow a deeper investigation of the molecular processes which pertain to large amplitude motions-in the molecules under study. They also bring evidence of puzzling effects which are tentatively explained.

\section{Acetylacetone family and NSC in hydrogenated matrices.}

Fully hydrogenated acetylacetone AcAcH8. The experiments in $p \mathrm{H}_{2}$ described in ref. 11 were reproduced with the new set-up at $2.8 \mathrm{~K}$. The use of the closed cycle cryostat allows keeping matrix without evaporation for longer times and we were able to record the IR spectra during five days (instead of $24 \mathrm{~h}$ in our previous experiments). Figure 2 shows the initial and the final spectra (panels $a$ and $b$ respectively). Comparison between the two spectra shows clearly a time evolution at the day scale. The same observation was done in ref. 11 , where the spectrum was deconvoluted in two components, one decreasing in time (less stable species) and the other increasing with time (most stable species, whose spectrum is reproduced in Figure 2, panel c for comparison).

The time evolution of the spectrum was attributed to the NSC process in the guest molecule. More precisely, it is essentially due to NSC within the methyl group bonded to $\mathrm{C}=\mathrm{O}$. As shown in figure 1, the two methyl groups of AcAc are non-equivalent, with different orientations facing the central $\mathrm{CH}$ group. The full pattern of torsional levels in AcAc is made complex because of the presence of these two methyl groups coupled with the $\mathrm{H}$ transfer. ${ }^{19}$ Nevertheless, theoretical calculations predict indeed a substantially lower rotational barrier for the methyl group on the $\mathrm{C}=\mathrm{O}$ side (noted hereafter $m_{\mathrm{CO}}$ ) than for the other methyl: ${ }^{11,20} 32 \mathrm{~cm}^{-1}$ for $m_{\mathrm{CO}}$ vs $411 \mathrm{~cm}^{-1}$ for the other methyl in DFT calculations at the B3LYP/6-311G(3df,3pd) level of theory. Hence, the torsional levels of the lowest energy are split by tunnelling through this particular periodic torsional potential in sub-levels of different symmetries ( $E$ and $A$ ) with a larger gap for $m_{\text {CO }}$ than for the other methyl. Because of the parity constrain of the total wavefunction, the $E$ and $A$ levels are not associated with the same nuclear-spin combination of the three $\mathrm{H}$-atoms in the $m_{\text {co }}$ group. The lowest level $(A)$ is associated with the nuclear spin $\mathrm{I}=3 / 2$ and the other one $(E)$ with $\mathrm{I}=1 / 2$. At the low temperature of the $p \mathrm{H}_{2}$ matrix, the $\mathrm{E}$ and A levels of lowest energy are thus populated by molecules differing by the nuclear spins of the $m_{\mathrm{CO}}$ hydrogens. In a first approximation, the NSC process mentioned in the introduction is assigned to NSC in $m_{\text {Co }}$ hydrogens and is observed due to the thermal relaxation at $3 \mathrm{~K}$ from $\mathrm{E}$ to $\mathrm{A}$ states within the $m_{\mathrm{CO}}$ group. Due to the presence of the second methyl group, each of these states contains in fact several levels ${ }^{19}$ and we will call them pseudo $E$ and A states, noted " $A$ " and " $E$ " respectively. Hence, the observed spectrum is a superposition of two spectra. One is associated with absorption from the " $A$ " state of lowest energy and the other to the " $E$ " state. From the analysis of ref. 11, the most stable species is assigned to AcAcH 8 in the lowest " $A$ " state of the $m_{\text {CO }}$ rotor (spectrum displayed in Figure 2c). Several bands of " $A$ " and " $E$ " spectra are clearly distinct. They concern specific modes. For example, the -OH out-of-plane bending mode around $950 \mathrm{~cm}^{-1}$ has a " $A$ " component at $950 \mathrm{~cm}^{-1}$ and a "E" component at $961 \mathrm{~cm}^{-1}$ (see Figure 2). Other "doublet" structures associated with " $A$ " and " $E$ " components are observed when comparing Figures $2 a$ and 2b. A very important point regarding the present work concerns very specific modes where the " $E$ " component is much broader than the " $\mathrm{A}$ " component. Such a situation is met in Figure 2 with the bands at $1250 \mathrm{~cm}^{-1}$ and $1463 \mathrm{~cm}^{-1}$, 


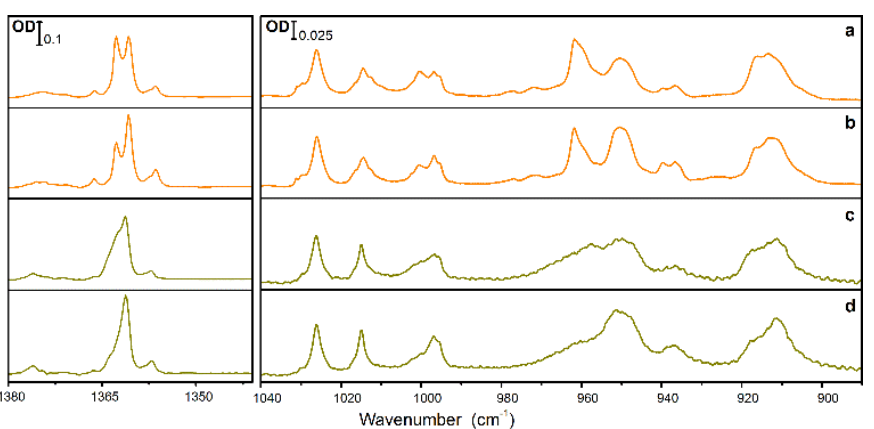

showing broad blue wings of higher intensity in $2 \mathrm{a}$ than in $2 \mathrm{~b}$ and missing in 2c. These wings were assign to the " $E$ " spectrum. $^{11}$

Turning back to the present results in Figure 2, the IR spectrum of panel b) is not identical to that of panel c). Hence, even after five days, the spin relaxation is not completed and a small amount of torsionally excited $\mathrm{AcAcH} 8$ is still present in the sample. The ratio " $\mathrm{A}$ "/" $\mathrm{E}$ " between the two components is measured as $9.00 \pm 0.05$ at the end of the present experiment, while it was $0.96 \pm 0.05$ in the as-deposited sample.

Figure 3: Zooms on parts of IR spectra of $\mathrm{AcAcH} 8$ (a) and (b) in $p \mathrm{H}_{2}$ (same sample as in Figure 2, $\left.0.01 \% \circ \mathrm{oH}_{2}\right)$, as deposited and $22 \mathrm{~h}$ later, respectively; (c) and (d) in $\mathrm{H}_{2}(22 \%$ $o \mathrm{H}_{2}, 78 \% p \mathrm{H}_{2}$ ), as deposited and $22 \mathrm{~h}$ later, respectively.

NSC from ortho- to para-hydrogen is also observed in the host itself because of the presence of $\mathrm{oH}_{2}$ impurities. These impurities are inherent to $\mathrm{pH}_{2}$ solids and induce weak spectral changes in the guest bands. ${ }^{3,21,22}$ We performed experiments where the $\mathrm{AcAcH} 8 / \mathrm{pH}_{2}$ samples contain various amounts of $\mathrm{oH}_{2}$ in order to check that the time evolution of the spectral bands was not due simply to the $\mathrm{oH}_{2}-\mathrm{pH}_{2} \mathrm{NSC}$ when one or several $\mathrm{oH}_{2}$ molecules form a complex with AcAcH8. The amount of $\mathrm{oH}_{2}$ was varied from $0.01 \%$ to a few \%, as estimated either from the temperature of the converter or from the intensity of the $\mathrm{oH}_{2}$ band at $4153 \mathrm{~cm}^{-1}$. 23 The comparison of the spectrum displayed in the present Figure 2a (sample with $0.01 \% \mathrm{oH}_{2}$ ) with that given in Figure 2a of Ref. 11 (sample with $0.7 \% \mathrm{oH}_{2}$ ) shows that the presence of a small amount of $\mathrm{oH}_{2}$ does not modify considerably the observed vibrational bands compared to the changes discussed above between metastable and stable components of the spectrum. This confirms the assignment of the latter changes to the transitions from " $E$ " and " $A$ " rather than to complexation with $\mathrm{oH}_{2}$.

Complexation of AcAcH8 with $\mathrm{oH}_{2}$ can be achieved on purpose when large amounts of $\mathrm{oH}_{2}$ is present in the $\mathrm{pH}_{2}$ matrix. Figure 3 displays the results obtained in a sample containing a large amount of $\mathrm{oH}_{2}$ (22\% after deposition) and kept one day long to illustrate the combination of time and $\mathrm{oH}_{2}$ effects on $\mathrm{AcAcH} 8$ vibrational features. Only the most significant parts of the IR spectra are shown in Figure 3, i.e. the vibrational bands with quite distinct " $\mathrm{A}$ " and " $\mathrm{E}$ " components in $\mathrm{pH}_{2}$; panels a and $\mathrm{b}$ correspond to spectra obtained with the sample of Figure 2 for easier comparison with the $\mathrm{H}_{2}\left(22 \% \mathrm{oH}_{2}\right)$ sample displayed in panels $\mathrm{c}$ and d; panels a and c correspond to as-deposited samples whilst panels $b$ and $d$ correspond to the same samples $22 \mathrm{~h}$ later, respectively. In the selected spectral ranges, the " $\mathrm{A}$ " components are at lower energies than the " $E$ " components. Even with a large amount of $\mathrm{oH}_{2}$, the "A" component is strong (see for example at 1361 and $950 \mathrm{~cm}^{-1}$ in Figure 3c), whereas it should be very weak if this component were assigned to AcAcH8 without $\mathrm{oH}_{2}$ as nearest neighbours. The bands showing distinct " $A$ " and " $E$ " components in $p \mathrm{H}_{2}$ are less structured in $\mathrm{H}_{2}\left(22 \% o \mathrm{H}_{2}\right)$. However a time evolution is observed (compare $c$ and $d$ panels of Figure 3 ) exhibiting the same tendency as in $p \mathrm{H}_{2}$, assigned to NSC from " $E$ " to " $A$ ".

Because of its quadrupole moment, $\mathrm{oH}_{2}$ has specific electrostatic interactions with the guest molecules. ${ }^{3,4}$ Our photoisomerisation study of $\mathrm{AcAcH} 8$ in hydrogen solids has shown that these interactions allow the detection of an additional open isomer of AcAcH8 in $n \mathrm{H}_{2}$ which is not observed in $\mathrm{pH}_{2}{ }^{24}$ This specific isomer was found to isomerize to a more stable form in $p \mathrm{H}_{2}$ by a tunnelling process, ${ }^{25}$ which is quenched in $n \mathrm{H}_{2}$ by the additional quadrupole interaction. Taking this peculiar interaction between $\mathrm{oH}_{2}$ and AcAcH8 into account, we propose a tentative scheme to rationalize the available observations. When AcAcH8 is complexed with $\mathrm{oH}_{2}$ molecules, the concerted $\mathrm{H}$-atom transfer mechanism where the methyl torsions are involved may be reduced and the torsional barrier of $m_{\mathrm{CO}}$ increased. The "E"- "A" splitting is therefore reduced or even suppressed in both the ground state and the vibrational levels.

A first consequence of this model is that AcAcH8 complexed with $\mathrm{oH}_{2}$ has a single absorption line (or two very close ones) whatever the mode which is excited. The red components in the $\mathrm{oH}_{2}$ experiments, at about the same location as in the pure $p \mathrm{H}_{2}$ experiments, would correspond to these single lines. A second consequence is when an $\mathrm{oH}_{2}$ molecule which is complexed with $\mathrm{AcAcH} 8$ experiences a NSC and switches to $p \mathrm{H}_{2}$. Before the $o \mathrm{H}_{2}-p \mathrm{H}_{2}$ conversion, the nearly degenerated " $E$ " and " $A$ " states are almost equally populated the matrix temperature ( $3 \mathrm{~K})$. Upon $\mathrm{oH}_{2}-p \mathrm{H}_{2}$ conversion, " $\mathrm{E}$ " and " $A$ " state splitting increases. Actually, with $22 \% \mathrm{oH}_{2}$ in the sample, several $\mathrm{oH}_{2}$ molecules are complexed with AcAcH8. The " $\mathrm{E}$ " and " $A$ " splitting may therefore appear as a "semi-continuum", depending on the number of $\mathrm{oH}_{2}$ molecules and the number of $o \mathrm{H}_{2}-\mathrm{pH}_{2}$ conversions which are involved. This is in line with the absence of band structures in $\mathrm{H}_{2}\left(22 \% \mathrm{oH}_{2}\right)$ and the enlarged blue sides of the bands in Figure $3 \mathrm{c}$ instead of the clear blue components in Figure 3a.

With such a model, the observed time evolution would reflect two NSC processes which have opposite spectral consequences: NSC within the AcAcH 8 methyl groups and the $o \mathrm{H}_{2}-p \mathrm{H}_{2}$ conversion. As just discussed, the $o \mathrm{H}_{2}-p \mathrm{H}_{2}$ conversion induces a change of the " $E$ "- " $A$ " splitting, which switches from very small to its value in pure $p \mathrm{H}_{2}$. Before conversion, the " $\mathrm{E}$ " and " $A$ " components are almost equally populated and the very slow $o \mathrm{H}_{2}-p \mathrm{H}_{2}$ conversion feeds these two components in 


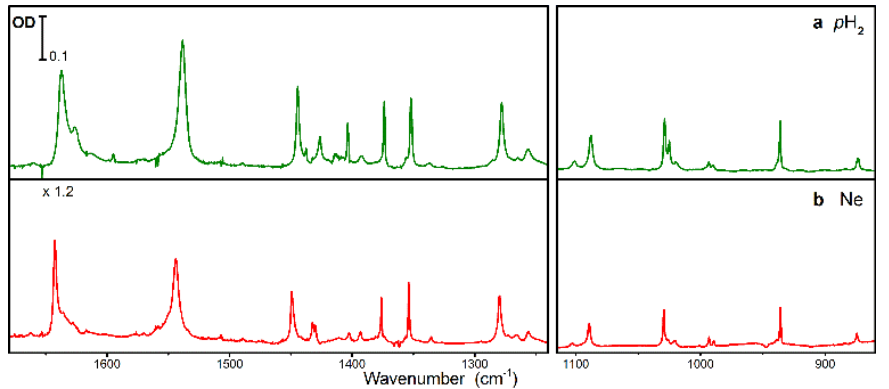

Figure 5: Infrared spectra (after subtraction of $\mathrm{AcAcH} 8$ and monodeuterated isotopologues) of double deuterated acetylacetone (AcAcD2) in (a) para-hydrogen and (b) neon matrices.

equal amounts when the " $E$ "-" $A$ " splitting has switched to its pure $p \mathrm{H}_{2}$ value. This is consistent with the persistent observation of " $E$ " components. Then the " $E$ "- " $A$ " conversion itself proceeds in molecules for which the "E"/" $A$ " ratio of population is out of thermal equilibrium. The global result is a decrease with time of all the " $E$ " components as observed experimentally (Figure 3d).

Double deuterated acetylacetone AcAcD2 in $\mathrm{pH}_{2}$. Since the methyl torsions are coupled with the hydrogen transfer in acetylacetone (a D-atom transfer in AcAcD2), it is interesting to compare the spectral behaviour of $\mathrm{AcAcH} 8$ in $p \mathrm{H}_{2}$ to that of AcAcD2. Figure 4 displays the IR spectrum of $A c A c D 2$ in $p \mathrm{H}_{2}$ matrix just after deposition. It shows much narrower lines than AcAcH8 (Figure 2a). Strikingly, the AcAcD2 spectrum in $p \mathrm{H}_{2}$ is very similar to that observed when AcAcD2 is isolated in a neon matrix. ${ }^{25}$ The latter is displayed in Figure 4, for comparison.

This is in strong contrast with the observations of AcAcH8 where many vibrational bands are broader and more structured in $p \mathrm{H}_{2}$ than in $\mathrm{Ne}$, due to the superposition of the spectra from " $A$ " and " $E$ " levels in the quantum matrix. ${ }^{11}$ Table 1 reports the experimental frequencies in $\mathrm{pH}_{2}$ and $\mathrm{Ne}$, together with the theoretical predictions given in ref. 25.

The deuteration effect is important on almost all the vibrational bands and, as just said, in about the same way as in $\mathrm{Ne} .{ }^{25} \mathrm{~A}$ band narrowing upon deuteration was expected in all the bands involving a $-\mathrm{OH}(\mathrm{D})$ motion because of the more localized deuterium atom in the $\mathrm{IHB} .^{26}$ In particular the $-\mathrm{OH}(\mathrm{D})$ bending is at play in many vibrational modes and the deuteration of the hydroxyl group affects a lot of bands. One can also notice that the OD stretching mode is detected as a very broad band around $1990 \mathrm{~cm}^{-1}$ whereas the $\mathrm{OH}$ stretching mode was not observed in the spectrum of $\mathrm{AcAcH} 8 / \mathrm{pH}_{2}$ because of a too strong broadening.

As expected from the similarities between spectra in $\mathrm{pH}_{2}$ and in $\mathrm{Ne}$, a time evolution of the AcAcD2 bands is hardly detected when looking for NSC in $m_{\text {CO }}$. Only slight changes in some bands are observed when keeping the matrix during few days. This strongly different behaviour between $\mathrm{AcAcH} 8 / p \mathrm{H}_{2}$ and AcAcD2 $/ p \mathrm{H}_{2}$ samples is a further evidence that NSC in the

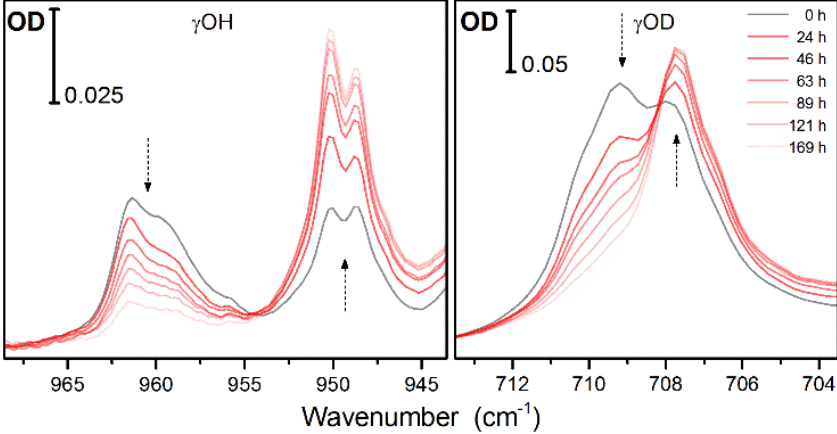

methyl groups is a signature of the efficiency of the concerted mechanism between methyl group torsion and $\mathrm{H}$-atom transfer.

The most important time evolution in $A c A c D 2 / p \mathrm{H}_{2}$ is detected in the band around $708 \mathrm{~cm}^{-1}$, assigned to the -OD out-of-plane bending mode $\left(\gamma_{O D}\right)$. It is in agreement with the $\mathrm{AcAcH} 8$ changes where the larger shift between " $E$ " and " $A$ " spectra was detected in the $\gamma_{\mathrm{OH}}$ band. ${ }^{11}$ Right panel of Figure 5 shows

Figure 4: Time evolution of $\gamma \mathrm{OH}$ (left panel) and $\gamma \mathrm{OD}$ (right panel) bands in an AcAcD2/pH2 sample including totally hydrogenated and monodeuterated acetylacetone as impurities.

the time evolution of this band in a sample kept at $3 \mathrm{~K}$ during eight days. This specific sample contained $\mathrm{AcAcH} 8$ and monodeuterated acetylacetone as impurities and the time evolution of the $\gamma_{\mathrm{OH}}$ band assigned to these species in the same sample is also displayed in Figure 5, left panel (in $\mathrm{Ne}$, the frequency shift between the $\gamma_{\mathrm{OH}}$ modes of $\mathrm{AcAcH} 8$ and the monodeuterated isotopologue $\left(0.5 \mathrm{~cm}^{-1}\right)$ was much smaller than the bandwidth $\left(5 \mathrm{~cm}^{-1}\right)^{25}$ and the two species were difficult to distinguish in the spectra of Figure 5). The frequency gap between the $\gamma_{O D}$ bands in " $E$ " and " $A$ " states is reduced to $1.4 \mathrm{~cm}^{-1}$ while it is $11 \mathrm{~cm}^{-1}$ in the $\gamma_{\mathrm{OH}}$ mode. Obviously, the torsional energy brought in the "E" state has only a very weak influence on the IR spectrum of AcAcD2.

Table 1: Experimental frequencies of the chelated enol form of AcAcD2 in neon and para-hydrogen matrices, compared to calculated harmonic frequencies [B3LYP/6 $311++\mathrm{G}(3 \mathrm{df}, 3 \mathrm{pd})]\left(\mathrm{cm}^{-1}\right)$. Intensities $(\mathrm{km} / \mathrm{mol})$ obtained in the harmonic approximation.

\begin{tabular}{|c|c|c|c|c|}
\hline \multirow{2}{*}{ Assignment $^{a}$} & \multicolumn{2}{|c|}{ Experiment } & \multicolumn{2}{|c|}{ Theoretical $^{\mathrm{b}}$} \\
\hline & $p \mathrm{H}_{2}$ & $\mathrm{Ne}^{\mathrm{b}}$ & \multicolumn{2}{|c|}{$\begin{array}{c}\text { harmonic*sf }^{\mathrm{c}} \\
\text { (Intensity) }\end{array}$} \\
\hline $\mathrm{v}_{\mathrm{a}} \mathrm{CH}_{3}$ (CO side) & & $3034^{d}$ & 3083.2 & (10) \\
\hline $\mathrm{V}_{\mathrm{a}} \mathrm{CH}_{3}(\mathrm{OH}$ side $)$ & 3015 & $3027^{d}$ & 3078.3 & (9) \\
\hline $\mathrm{V}_{\mathrm{a}} \mathrm{CH}_{3}(\mathrm{OH}$ side) & & & 3031.5 & (5) \\
\hline $\mathrm{v}_{\mathrm{a}} \mathrm{CH}_{3}(\mathrm{CO}$ side $)$ & $29 / 1$ & & 3029.5 & (6) \\
\hline $\mathrm{V}_{\mathrm{s}} \mathrm{CH}_{3}$ (OH side) & 2935 & $2951^{d}$ & 2980.5 & (8) \\
\hline $\mathrm{v}_{\mathrm{s}} \mathrm{CH}_{3}$ (CO side) & 2928 & & 2976.4 & (3) \\
\hline$v C D$ & 2299 & 2304.5 & 2328.7 & (1) \\
\hline vOD & $1991^{\mathrm{e}}$ & $2000^{d}$ & 2158.3 & (259) \\
\hline$v_{a}(C=C+C=0)$ & 1637.2 & 1641.8 & 1631.7 & (263) \\
\hline$v_{s}(C=C+C=O)+\delta O D$ & 1538.5 & 1544.2 & 1530.6 & (374) \\
\hline$\delta_{\mathrm{a}} \mathrm{CH}_{3}(\mathrm{OD}$ side $)$ & 1444.6 & 1449.4 & 1448.3 & $(87)$ \\
\hline $\mathrm{\delta}_{\mathrm{a}} \mathrm{CH}_{3}(\mathrm{CO}$ side $)$ & 1426.3 & 1429.3 & 1436.9 & (39) \\
\hline${ }_{5} \mathrm{CH}_{3}$ (OD side) & 1392.9 & 1392.7 & 1391.5 & (28) \\
\hline$\delta_{5} \mathrm{CH}_{3}$ & 1374.0 & 1376.1 & 1376.8 & (11) \\
\hline$\delta_{\mathrm{s}} \mathrm{CH}_{3}(\mathrm{CO}$ side $)$ & 1352.3 & 1354.0 & 1358.5 & (54) \\
\hline $\mathrm{V}_{\mathrm{S}} \mathrm{C}-\mathrm{C}-\mathrm{C}=\mathrm{C}-\mathrm{C}$ ring breath & 1278.0 & 1279.5 & 1278.4 & (126) \\
\hline
\end{tabular}




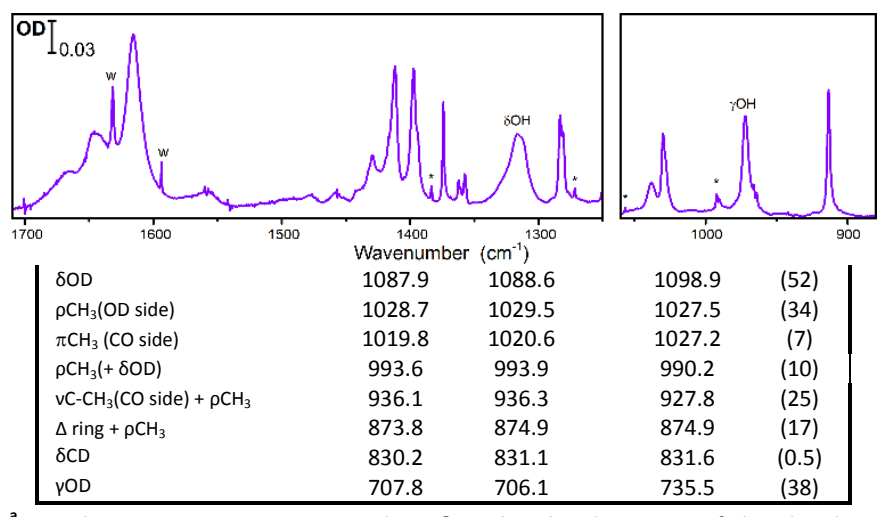

${ }^{a}$ main characteristic motions; $v$, stretching; $\delta$, in plane bending; $\boldsymbol{v}$, out of plane bending $\rho$, in plane rocking; $\pi$, out of plane rocking; $\Delta$, in plane ring deformation; $\mathbf{s}$, symmetric; a, asymmetric; ${ }^{b}$ from reference 25 ; 'sf: scaling factor $(0.981) ;{ }^{d}$ broad bands; ${ }^{e}$ very broad band, the center is not well defined

In our DFT calculations at the B3LYP/6-311++G(3df,3pd) level of theory, the torsional harmonic frequencies localized in $m_{\mathrm{CO}}$ are the same in AcAcH8 and AcAcD2 $\left(28 \mathrm{~cm}^{-1}\right)$ indicating similar rotational wells. ${ }^{16,24,25}$ Nevertheless, because of the coupling with the $\mathrm{H}$ or $\mathrm{D}$ transfer, the energy gap between " $\mathrm{E}$ " and " $A$ " ground states depends on the deuteration. Without theoretical investigations, the decrease due to deuteration is difficult to estimate. The tunnelling splitting related to $m_{\text {CO }}$ was measured in solid acetylacetone by means of neutron scattering: its value was reduced in AcAcD2 to $76 \%$ of the AcAcH8 splitting. ${ }^{27}$ The deuteration effect highlighted in Figures 4 and 5 underlines the reduced hydrogen transfer in AcAcD2.

3-chloro acetylacetone $\mathrm{AcAcCl}$ in $\mathrm{pH}_{2}$. The substitution of $\mathrm{H}$ by $\mathrm{Cl}$ in the alpha position has an important effect on the structure of the molecule as shown in Figure 1: the two methyl groups have symmetric orientations versus the $\mathrm{C}-\mathrm{Cl}$ axis in $\mathrm{AcAcCl}{ }^{28}$ The consequence is that the $\mathrm{H}$ transfer is no longer coupled with the methyl torsions in this molecule.

Figure 6 shows the IR spectrum of $\mathrm{AcAcCl}$ in $\mathrm{pH}_{2}$. Some bands are especially broad. They are associated with modes involved in the $\mathrm{H}$ bond, for example the $\mathrm{OH}$ in-plane bending mode $\left(\delta_{\mathrm{OH}}\right)$ marked in the figure. The $\gamma_{\mathrm{OH}}$ band is observed at $972 \mathrm{~cm}$ 1 , i.e. at a higher frequency than the $\gamma_{\mathrm{OH}}$ band of $\mathrm{AcAcH} 8$ located at $950 \mathrm{~cm}^{-1}$ in $\mathrm{pH}_{2}$. It is in agreement with a stronger $\mathrm{IHB}$ in $\mathrm{AcAcCl}$, as previously observed and theoretically predicted. ${ }^{28-30}$ The strength of the IHB is due to steric effects: the repulsion between lone pairs of $\mathrm{Cl}$ and $\pi$ electrons of the pseudocycle induces a decrease of the $0 \cdots 0$ distance. ${ }^{28}$

Waiting for days to observe a NSC effect was unsuccessful, as expected. Theoretically, the lowest torsional frequency is predicted much higher (at $78 \mathrm{~cm}^{-1}$ at the B3LYP/6$311++G(3 d f, 3 p d)$ level of theory) than for $m_{\mathrm{CO}}$ in $\mathrm{AcAcH} 8$. It implies higher torsional barriers and smaller tunnelling splittings for both methyl groups. In such cases, the related $\mathrm{E}$ and $A$ levels can be more or less equally populated at $3 \mathrm{~K}$. In these conditions, NSC in the methyl groups of $\mathrm{AcAcCl}$ cannot be observed in our experiments. As the $\mathrm{H}$ transfer is not coupled with methyl torsions, a vibrational excitation can promote the $\mathrm{H}$ transfer in similar ways for all the torsional levels. The energy difference between the levels of different symmetries is not large enough to distinguish their absorption spectra in the matrix.

The example of $\mathrm{AcAcCl}$, involving a strong IHB (stronger than in AcAc), demonstrates again the specificity of the results obtained with AcAc in $p \mathrm{H}_{2}$, due to the internal characteristics of AcAc with methyl torsions entangled with $\mathrm{H}$ transfer, and not to guest/host interactions.

NSC in AcAc: Kinetics. The rate of NSC between " $E$ " and " $A$ " states of AcAc is very slow, at the day scale. It has the same order of magnitude as NSC in the methyl groups of small molecules embedded in $p \mathrm{H}_{2}{ }^{7,31}$ Its observation is very challenging and only very few samples were kept at $3 \mathrm{~K}$ during days to perform kinetic studies. The very slow NSC process is sensitive to the presence of impurities and to the amount of guest molecules in the sample. A quantitative kinetic study is therefore difficult and only tendencies are reported below.

In the spectra of $\mathrm{AcAcH} 8 / \mathrm{pH}_{2}$ shown in Figure $2 \mathrm{a}$ and $2 \mathrm{~b}$, the amount of $\mathrm{oH}_{2}$ is very small ( $\leq 0.01 \%$ ) and the rate of NSC is estimated to $0.021 \mathrm{~h}^{-1}$. It is slower than the value of $0.045 \mathrm{~h}^{-1}$ reported in ref. 11 obtained in a sample carrying $0.7 \% \mathrm{oH}_{2}$. This is not surprising given examples reported where the NSC rate is enhanced in the presence of $o \mathrm{H}_{2}$ impurities. ${ }^{7,32}$

The spectrum taken from a sample enriched with $\mathrm{oH}_{2}$ is shown in Figure 3. The experimental conditions were similar to those of Ref. 11 (i.e. using the SMC cryostat). Surprisingly, and in apparent contradiction with the previous assessment on the $\mathrm{oH}_{2}$ effects, the NSC rate was estimated at least a factor two slower than in the comparable experiment in $\mathrm{pH}_{2}$. In fact, this slowed down rate can be interpreted by the opposite effects of NSC in $\mathrm{H}_{2}\left(\mathrm{oH}_{2} \rightarrow p \mathrm{H}_{2}\right.$ conversion) and NSC in AcAc, as discussed previously. A decrease of the NSC rate in clustering with $\left(\mathrm{oH}_{2}\right)_{n}$ was already observed in the study of water in $\mathrm{pH}_{2}$ solids. $^{18}$

From our experiments with the deuterated species, it was not possible to extract a clear conclusion on the deuteration effect on the NSC kinetics. The rates of NSC in the hydrogenated or mono and double deuterated AcAc are similar, as illustrated in Figure 5.

The simplified picture of " $\mathrm{E}$ " and " $\mathrm{A}$ " states is consistent with the measurement of an equal population of these states in the initial spectrum of AcAcH8 (Figure 2a). This actually reflects the populations of these states at room temperature before the matrix deposition. The population ratio between these two " $A$ " and " $E$ " states when, at long time, $\mathrm{AcAcH} 8$ is at equilibrium at the matrix temperature is a way to quantify the tunnelling splitting $\Delta \mathrm{E}$ in the ground state: $\Delta \mathrm{E}=k T \ln \left(\left[{ }^{\prime} \mathrm{A}\right]_{\mathrm{T}} /[\text { " } \mathrm{E} \text { " }]_{\mathrm{T}}\right)$ where $[X]_{T}$ is the population of $X$ state at the thermal equilibrium at the temperature $T$, taking into account that the degeneracy of " $A$ " and " $E$ ", including nuclear spin statistics, are the same. In practice, such a measurement is very difficult to achieve 
because the quality of the observed spectrum becomes extremely bad when the isolation time is very long. Hence, full equilibrium cannot be reached. Only a lower bound $\Delta E>5 \pm 1$ $\mathrm{cm}^{-1}$ can be given. This value is similar to that reported for the free rotation of the methyl group of $\mathrm{CH}_{3} \mathrm{~F}$ in $\mathrm{pH}_{2}{ }^{7}$ It highlights a valuable enhancement of the $\mathrm{E}-\mathrm{A}$ splitting in a methyl torsion by coupling with the $\mathrm{H}$ transfer. Theoretical calculations taking into account all the couplings at play in AcAc possibly explain this result, ${ }^{19}$ but further theoretical investigations would be necessary for a full understanding.

Vibrational analysis. The differences between the spectra of " $E$ " and " $A$ " states reflect the effect of a small amount of torsional energy on vibrational transitions. In AcAc, the $\mathrm{H}$-transfer is realized in a concerted mechanism involving both (i) a rearrangement between the $\mathrm{C}-\mathrm{C}$ and $\mathrm{C}=\mathrm{C}$ (resp. $\mathrm{C}-\mathrm{O}$ and $\mathrm{C}=\mathrm{O}$ ) bonds of the pseudo cycle and (ii) methyl torsions. H-transfer will be easier from the " $E$ " state when combined with welladapted in-plane vibrations. Actually, when a small amount of torsional energy is present in $m_{\mathrm{CO}}$ (" $\mathrm{E}$ " state), many vibrational modes of AcAcH8 are affected, especially those participating to the $\mathrm{H}$-transfer. In particular, we observed a broadening of the bands from the " $A$ " spectrum to the " $E$ " one, more or less pronounced, depending on the mode. This is presented in the supplementary material of Ref. 11 but not discussed, given the format of this publication. This is partly highlighted in Figure 2 and discussed hereafter in the light of the mode description performed in our B3LYP/6-311++G(3df,3pd) calculations (see in particular the supplementary material of Ref. 11)..$^{11,25}$

The largest shift between " $E$ " and " $A$ " bands is measured in the $\gamma_{\mathrm{OH}}$ mode $\left(\sim 11 \mathrm{~cm}^{-1}\right)$ with a higher frequency in the " $\mathrm{E}$ " state. This mode is well localized on the hydroxyl group in that kind of molecules, and its frequency increases with the strength of the IHB. We know from the "NSC in AcAc: Kinetics" section above that the "E"-"A" splitting is quite large in AcAcH8. It puts the "E" level not far from the top of the $m_{C O}$ torsional barrier Likely, the corresponding wavefunction has a quite large extension along the torsion coordinate. In this context, the observed blue shift is in agreement with calculations performed on the corresponding transient rotamer involving symmetric methyl groups (i.e. with a $\pi / 3$ rotation of $m_{\mathrm{CO}}$ ), ${ }^{11}$ and is consistent with a much easier $\mathrm{H}$-transfer in the " $\mathrm{E}$ " level. In the $900-1000 \mathrm{~cm}^{-1}$ spectral range, two other modes show significant changes whether " $A$ " or " $E$ " spectra are considered: a blue shift $\left(\sim 5 \mathrm{~cm}^{-1}\right)$ and broadening from " $A$ " to " $E$ ". These modes, with maxima at 997 and $911 \mathrm{~cm}^{-1}$ in the spectrum of Figure $3 \mathrm{~b}$, involve the rocking of $m_{\mathrm{CO}}$ and affect the $\mathrm{O} \cdots \mathrm{H}-\mathrm{O}$ geometry.

$A$ " $A$ " to " $E$ " blue shift of $2 \mathrm{~cm}^{-1}$ is also clearly observed in the narrow and intense band near $1362 \mathrm{~cm}^{-1}$ (Figure 3). It is assigned to the umbrella bending mode of $m_{\mathrm{CO}}$. The narrowness of the " $A$ " and " $E$ " bands underlines the absence of coupling of that mode with the IHB. Likewise, the out-ofplane bending mode of the $\mathrm{CH}$ olefinic group (observed at $\sim 770 \mathrm{~cm}^{-1}$ ) appears also as a narrow band. In contrast with $\gamma_{\mathrm{OH}}$, it shows a red shift $\left(1.8 \mathrm{~cm}^{-1}\right)$ from " $A$ " to " $E$ " states, indicating less steric constraints in the " $E$ " state.

The in-plane bending motion of the hydroxyl group $\left(\delta_{\mathrm{OH}}\right)$ is involved in several modes of $\mathrm{AcAcH} 8$ detected in the 1200 $1700 \mathrm{~cm}^{-1}$ spectral range. The $\delta_{\mathrm{OH}}$ contribution is dominant in the band around $1290 \mathrm{~cm}^{-1}$. It is very broad, ca $80 \mathrm{~cm}^{-1}$, as shown in figure $2 \mathrm{c}$ where the " $\mathrm{A}$ " component is extracted and appears as a kind of large "background". Its maximum cannot be determined accurately. This prevents observing a possible effect due to the $m_{\text {co }}$ torsional excitation. A narrower band (width of $9 \mathrm{~cm}^{-1}$ ) is detected in its vicinity at $1250 \mathrm{~cm}^{-1}$. Its blue wing observed in Figure $2 a$ (corresponding to the " $E$ " component) is much broader ( $c a 30 \mathrm{~cm}^{-1}$ ) than the " $A$ " component shown in Figure 2c. This reflects the effect of the $m_{\text {CO }}$ torsion on the coupling of this mode with the $\mathrm{H}$ transfer: this mode involves a $\delta_{\mathrm{OH}}$ motion which is not in phase with the pseudo cycle deformation accompanying the $\mathrm{H}$ transfer, in contrast with the former mode around $1290 \mathrm{~cm}^{-1}$. The vibrational enhancement of the $\mathrm{H}$-transfer is not strong in the " $A$ " state for that latter mode, whilst an additional torsional energy helps thus a lot to induce the $\mathrm{H}$-transfer.

More puzzling is the broadening in the " $E$ " state of the mode at $1463 \mathrm{~cm}^{-1}$. Its bandwidth increases by more than a factor seven when switching from the " $A$ " to " $E$ " spectrum (Figure 2): this mode involves very weakly a motion of the IHB part of the molecule and is more localized on the asymmetric bending (scissor) of the other methyl group $\left(m_{\mathrm{OH}}\right)$. This suggests that the promotion of both methyl motions can by itself enhance the coupling with the $\mathrm{H}$ transfer.

Surprisingly, the time evolution of the AcAcD2 spectrum does not highlight numerous vibrational effects related to NSC in $m_{\text {co. }}$. We saw indeed that the most obvious one concerns the $\gamma_{O D}$ mode. The "E"- "A" shift is reduced to $0.2 \%$ of the vibrational energy, five time less than for $\gamma_{\mathrm{OH}}$. One can distinguish very small blue shifts $\left(<0.5 \mathrm{~cm}^{-1}\right)$ in the bands at 874 and $1352 \mathrm{~cm}^{-1}$, assigned to modes involving bendings of $m_{\text {cO }}$. No significant broadening of the bands in the " $E$ " state is detected. Whereas the time evolutions on the $\gamma_{O H}$ and $\gamma_{O D}$ modes lead to " $E$ "/" $A$ " ratio of the same order at infinite time, the effect of the torsional energy in the " $E$ " state does not affect significantly the vibrational bands, i.e. the vibrational coupling with the $D$ transfer. The deuteration effect in the IHB is strong and appears to quench the torsional effects detected in AcAcH8.

These results show that a perturbation of one of the three large amplitude motions involved in the $\mathrm{H}$-transfer mechanism would affect severely the process, thus reducing substantially the efficiency of the concerted mechanism.

\section{Malonaldehyde family in $\mathrm{pH}_{2}$.}




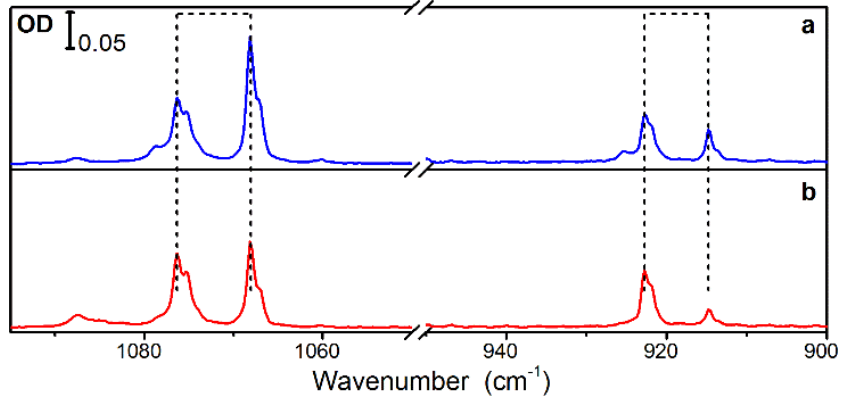

Without methyl groups, the molecules of the $\beta$-dialdehyde family under study involve the $\mathrm{H}$-transfer as single large amplitude motion. Malonaldehyde (MA) in its enol form, depicted in Figure 1, is the simplest molecule with an IHB in a pseudo aromatic ring system allowing a RAHB. Although the barrier in the $\mathrm{H}$-transfer seems higher in MA than in AcAc, ${ }^{33,34}$ a large splitting of energy levels due to the $H$ tunnelling process is observed in the isolated MA molecule. This is in line with the simplified $\mathrm{H}$ motion in this smaller molecule. This splitting was measured for the ground vibrational state ${ }^{35-37}$ and for various vibrational levels ${ }^{38-41}$ in the gas phase. Surprisingly, no tunnelling was observed for the molecule embedded in heavy matrices ${ }^{14,40,42,43}$ while it was detected for similar but larger molecules in the same kind of matrices. ${ }^{44,45}$ Because of the quantum properties of $\mathrm{pH}_{2}$ solids, one can expect that the $\mathrm{H}$ transfer will be less perturbed in $\mathrm{MA} / p \mathrm{H}_{2}$ samples. We performed a first attempt to isolate MA in the $p \mathrm{H}_{2}$ solid. The synthesis and the deposition of MA turned out to be difficult to achieve, resulting in spectroscopic data of bad

Figure 7: Doublets in the IR spectrum of $\mathrm{MACl}$ in $p \mathrm{H}_{2}$ (a) just after deposition; (b) one day later.

quality. However, a rough comparison with data in jet experiments suggests that $\mathrm{H}$-tunnelling is preserved in the $p \mathrm{H}_{2}$ environment. Further experiments to obtain better spectra are necessary to conclude.

MACl in $p \mathrm{H}_{2}$. A nice IR spectrum of the chlorine derivative ( $\mathrm{MACl}$, Figure 1) was obtained in $p \mathrm{H}_{2}$. A series of doublet bands appear in the spectrum. They are assigned to $\mathrm{H}$ tunnelling splitting. ${ }^{13}$ Our study brings an experimental proof of the weakening of the IHB by the chlorine substitution of the olefinic hydrogen of $\mathrm{MA}$, in agreement with theoretical predictions. ${ }^{13,46}$ This reduces the $\mathrm{H}$ tunnelling splitting of the ground state from MA $\left(21.6 \mathrm{~cm}^{-1}\right)^{37}$ to $\mathrm{MACl}$. Similar doublets are also detected when isolating $\mathrm{MACl}$ in $\mathrm{Ar}$ at $8 \mathrm{~K}$, i.e. at a much higher temperature, leading to assume that both levels are populated in $\mathrm{pH}_{2}$ at $3 \mathrm{~K}$, on the contrary of the MA case. ${ }^{13}$ Doublets correspond thus to vibrational excitation from both ground levels to both upper levels. They are clearly detected in two specific modes (see Figure 7) for which the tunnelling splitting in the upper level is large enough. The splitting is larger in $p \mathrm{H}_{2}$ than in $\operatorname{Ar}\left(\sim 8 \mathrm{~cm}^{-1}\right.$ versus $\left.\sim 5 \mathrm{~cm}^{-1}\right)$, in agreement with a less invasive environment in the case of the quantum matrix. Surprisingly, the $\mathrm{H}$ tunnelling process seems to be quenched in neon, since single bands are observed instead of doublets. ${ }^{13}$
In $p \mathrm{H}_{2}$, we observed an evolution of these two doublets with time, with an increase of the high frequency component and a decrease of the other, as shown in Figure 7. As the changes occur in the dark at the time scale of tens of hours, the process at play can be linked to NSC in the system. Due to the symmetry of the molecule, the two tunnelling levels in the ground state, which are of $A_{1}$ and $B_{2}$ symmetries in the permutation group $G_{4}$, are populated by molecules with different nuclear spins in the hydrogens of the $\mathrm{C}-\mathrm{H}$ bonds. ${ }^{47}$ However, assuming a small energy gap between these two levels, a significant population transfer from one to the other level by NSC in $\mathrm{MACl}$ is not expected. We performed additional experiments in $p \mathrm{H}_{2}$, in samples containing a small amount of $\mathrm{oH}_{2}$. With $\mathrm{ca} 2 \%$ of $\mathrm{oH}_{2}$, the doublets are essentially replaced by single bands at the frequencies of the low energy component of the doublets, i.e. at the frequencies of the components decreasing with time. We conclude that the NSC at play is a $\mathrm{oH}_{2} \rightarrow p \mathrm{H}_{2}$ conversion. This matches with observation reported above when AcAcH8 forms complexes with $\mathrm{oH}_{2}$. Again, the tunnelling process seems to be quenched with $\mathrm{oH}_{2}$ in the neighbourhood of the guest molecule, with a release of the $\mathrm{H}$ tunnelling due to NSC in $\mathrm{H}_{2}$. The effect of $\mathrm{oH}_{2}$ impurities, as in the case of $\mathrm{AcAcH} 8$, is thus to constraint large amplitude motions. One can notice that the influence of $\mathrm{oH}_{2}$ on $\mathrm{MACl}$ is observed even in matrices with less than $0.01 \%$ of $\mathrm{oH}_{2}$. It suggests a high mobility of $\mathrm{oH}_{2}$ toward the guest molecule, as was observed in $\mathrm{CH}_{3} \mathrm{~F} / p \mathrm{H}_{2}$ samples. ${ }^{21}$

The close matrix neighbourhood of the guest has thus a lot of influence on the $\mathrm{H}$-tunnelling process: tunnelling splitting in $\mathrm{MACl}$ observed in $\mathrm{Ar}$ and $p \mathrm{H}_{2}$, and not in $\mathrm{Ne}$, quenched in presence of $\mathrm{oH}_{2}$ in $p \mathrm{H}_{2}$, tunnelling process quenched in all rare gas matrices in the case of MA. Extended experiments are planned in order to better rationalize these intriguing observations.

\section{Conclusions}

We probed the weakness of the interaction between a guest molecule and the $\mathrm{pH}_{2}$ solid by investigating the environment effects on large amplitude motions of the guest and especially on the $\mathrm{H}$-transfer inside an intramolecular hydrogen bond.

We observed a tunnelling splitting of vibrational levels in molecules with a strong IHB, in 2-chloromalonaldehyde of the malonaldehyde family, in the "quantum" matrix of $\mathrm{pH}_{2}$ whereas the tunnelling process can be quenched in "classical" matrices. This tunnelling splitting is not observed in acetylacetone, even in the gas phase, because of the coupling with the torsion of methyl groups. However, $\mathrm{pH}_{2}$ solid offers a nice environment to test the methyl torsion as a large amplitude motion and its influence on the vibrational behaviour and the vibrational coupling with $\mathrm{H}$-transfer in the latter case. We can follow the nuclear spin conversion process between torsional levels and it opens new ways to document the role of methyl torsions in reactive processes. 
NSC in methyl groups was previously observed in $p \mathrm{H}_{2}$ in small methylated molecules (methyl fluoride, methanol). ${ }^{7,31}$ Its study in larger molecules, especially in molecules with entangled large amplitude motions, gives access to new spectroscopic information. To get spectroscopic evidence of NSC in methyl groups, the molecule must have a nearly free methyl rotor. Torsional barriers are usually too high in non-linear methylated larger molecules. The case of AcAc is specific and very interesting with its complex torsional-vibrational pattern.

The role of the traces of $o \mathrm{H}_{2}$ in $p \mathrm{H}_{2}$ solids can make harder the understanding of the vibrational spectra, in particular in the study of NSC processes. We addressed this problem in our study to highlight the specific behaviours of MA and AcAc derivatives in $\mathrm{pH}_{2}$.

There are still intriguing results that need a theoretical approach to be understood. In particular, we hope that our vibrational data will open the way to a theoretical analysis of the vibrational behaviour of the molecules of interest.

\section{Conflicts of interest}

There are no conflicts to declare.

\section{Acknowledgements}

This work was supported by the French Science Agencies (ANR06-BLAN-0314; RTRA Triangle de la Physique - 2010-004-T NOSTADYNE and 2013-0436T REACMAQ) and by the FrenchLithuanian PHC GILIBERT program (25405YJ and 32894YA). We acknowledge the use of the computing center MésoLUM of the LUMAT research federation (FR LUMAT 2764).

\section{References}

T. Momose and T. Shida, Bull. Chem. Soc. Jpn., 1998, 71, 115.

2 T. Momose, M. Fushitani and H. Hoshina, Int. Rev. Phys. Chem., 2005, 24, 533-552.

3 K. Yoshioka, P. L. Raston and D. T. Anderson, Int. Rev. Phys. Chem., 2006, 25, 469-496.

4 M. E. Fajardo, in Physics and Chemistry at Low Temperatures, ed. L. Khriachtchev, Pan Stanford Publishing Pte.Ltd., Singapore, Pan Stanfo., 2011, pp. 167-202.

$5 \quad$ M. Bahou, P. Das, Y.-F. Lee, Y.-J. Wu and Y.-P. Lee, Phys. Chem. Chem. Phys., 2014, 16, 2200-10.

$6 \quad$ I. F. Silvera, Rev. Mod. Phys., 1980, 52, 393-452.

7 Y. P. Lee, Y. J. Wu and J. T. Hougen, J. Chem. Phys., 2008, 129, 104502.

8 J. Ceponkus, W. Chin, M. Chevalier, M. Broquier, A. Limongi and C. Crépin, J. Chem. Phys.

9 R. R. Lozada-Garcia, J. Ceponkus, W. Chin, M. Chevalier and C. Crépin, Chem. Phys. Lett., 2011, 504, 142-147.
G. Gilli and P. Gilli, The Nature of the Hydrogen Bond, Oxford University Press, 2009.

R. R. Lozada-Garcia, J. Ceponkus, M. Chevalier, W. Chin, J. M. Mestdagh and C. Crépin, Angew. Chemie - Int. Ed., 2012, 51, 6947-6950.

12 T. N. Wassermann, Georg-August-Universität Göttingen, 2005.

A. Gutiérrez-Quintanilla, M. Chevalier, R. Platakyte, J. Ceponkus, G. Rojas-Lorenzo and C. Crépin, Phys. Chem. Chem. Phys., 2018, 20, 12888-12897.

D. W. Firth, P. F. Barbara and H. P. Trommsdorff, Chem. Phys., 1989, 136, 349-360.

P. Kin-Kin Dea, 'The Nature of the intramolecular hydrogen bonf in the enol tautomer of 2,4-pentanedione', California Institute of Technology, PhD Thesis., 1972.

A. Gutiérrez-Quintanilla, Molecules and complexes with hydrogen bond: solvation and photoreactivity in cryogenic matrices, Université Paris-Saclay - Université Paris-Sud, PhD thesis., 2016.

H. Ogoshi and K. Nakamoto, J. Chem. Phys., 1966, 45, 3113-3120.

M. E. Fajardo, S. Tam and M. E. DeRose, J. Mol. Struct., 2004, 695-696, 111-127.

Y. C. Chou, J. Mol. Spectrosc., 2010, 263, 34-43.

I. Matanović, N. Došlić and Z. Mihalić, Chem. Phys., 2004, 306, 201-207.

K. Yoshioka and D. T. Anderson, J. Chem. Phys., 2003, 119, 4731.

D. T. Anderson and L. O. Paulson, J. Phys. Chem. A, 2009, 113, 1770-1778.

S. Tam and M. E. Fajardo, Rev. Sci. Instrum., 1999, 70, 1926-1932.

R. R. Lozada-García, J. Ceponkus, M. Chevalier, W. Chin, J.M. Mestdagh and C. Crépin, Phys. Chem. Chem. Phys., 2012, 14, 3450-3459.

A. Gutierrez-Quintanilla, M. Chevalier and C. Crepin, Phys. Chem. Chem. Phys., 2016, 18, 20713-20725.

Z. Mielke and L. Sobczyk, in Isotope Effects In Chemistry and Biology, eds. A. Kohen and H. H. Limbach, Taylor \& Francis, CRC Press, Boca Raton, 2005, pp. 281-304. M. R. Johnson, N. H. Jones, A. Geis, A. J. Horsewill and H. P. Trommsdorff, J. Chem. Phys., 2002, 116, 5694-5700. S. F. Tayyari, M. Zahedi-Tabrizi, R. Afzali, S. Laleh, H. A. Mirshahi and Y. A. Wang, J. Mol. Struct., 2008, 873, 79-88. F. Dolati, S. F. Tayyari, M. Vakili and Y. A. Wang, Phys. Chem. Chem. Phys., 2016, 18, 344-350. A. F. Jalbout, M. Ali Naseri, M. Fazli, H. Raissi, M. Rezaei, A. Nowroozi and A. De Leon, Int. J. Quantum Chem., 2009, 109, 1481-1496. Y. P. Lee, Y. O. Wu, R. M. Lees, L. H. Xu and J. T. Hougen, Science, 2006, 311, 365-368. M. Miki and T. Momose, Fiz. Nizk. Temp., 2000, 26, 899908.

Y. Wang, B. J. Braams, J. M. Bowman, S. Carter and D. P. Tew, J. Chem. Phys., 2008, 128, 1-9.

S. A. Broadbent, L. A. Burns, C. Chatterjee and P. H. Vaccaro, Chem. Phys. Lett., 2007, 434, 31-37. 
S. L. Baughcum, R. W. Duerst, W. F. Rowe, Z. Smith and E. B. Wilson, J. Am. Chem. Soc., 1981, 103, 6296-6303.

36 S. Baughcum, Z. Smith, E. Wilson and R. Duerst, J. Am. Chem. Soc., 1984, 106, 2260-2265.

37 T. Baba, T. Tanaka, I. Morino, K. M. T. Yamada and K. Tanaka, J. Chem. Phys., 1999, 110, 4131-4133.

38 T. N. Wassermann, D. Luckhaus, S. Coussan and M. A. Suhm, Phys. Chem. Chem. Phys., 2006, 8, 2344-2348.

39 N. O. B. Lüttschwager, T. N. Wassermann, S. Coussan and M. A. Suhm, Phys. Chem. Chem. Phys., 2010, 12, 82018207.

40 N. O. B. Lüttschwager, T. N. Wassermann, S. Coussan and M. A. Suhm, Mol. Phys., 2013, 111, 2211-2227.

41 C. Duan and D. Luckhaus, Chem. Phys. Lett., 2004, 391, 129-133.

42 T. Chiavassa, P. Verlaque, L. Pizzala, A. Allouche and P. Roubin, J. Phys. Chem., 1993, 97, 5917-5925.

43 A. Trivella, S. Coussan, T. Chiavassa, P. Theulé, P. Roubin and C. Manca, Low Temp. Phys., 2006, 32, 1042-1049.

44 R. L. Redington and T. E. Redington, J. Mol. Spectrosc., 1979, 78, 229-247.

45 P. F. Barbara, P. K. Walsh and L. E. Brus, J. Phys. Chem., 1989, 93, 29-34.

46 J. N. Woodford, J. Phys. Chem. A, 2007, 111, 8519-8530.

47 E. S. Goudreau, Far-infrared synchrotron-based spectroscopy of proton tunnelling in malonaldehyde, The University of New Brunswick, PhD thesis., 2017. 